Somnologie $2016 \cdot 20: 238$

DOI 10.1007/s11818-016-0065-5

Online publiziert: 25 . Juli 2016

๑) Springer-Verlag Berlin Heidelberg 2016

CrossMark

\author{
Ingo Fietze ${ }^{1}$ Christoph Nissen ${ }^{1,2} \cdot$ Thomas Erler $^{1,3} \cdot$ Peter Young ${ }^{1,4}$ \\ 'Interdisziplinäres Schlafmedizinisches Zentrum, Charité - Universitätsmedizin Berlin, Berlin, Deutschland \\ ${ }^{2}$ Klinik für Psychiatrie und Psychotherapie, Universitätsklinikum Freiburg, Freiburg, Deutschland \\ ${ }^{3}$ Klinik für Kinder- und Jugendmedizin, Klinikum Westbrandenburg GmbH, Potsdam, Deutschland \\ ${ }^{4}$ Klinik für Schlafmedizin und neuromuskuläre Erkrankungen, Universitätsklinikum Münster, Münster, \\ Deutschland
}

\title{
Erratum zu: Non-24: eine unterschätzte zirkadiane Schlafstörung bei Blinden
}

\section{Erratum zu:}

Somnologie (2016) 20:119-124.

DOI $10.1007 / \mathrm{s} 11818-016-0060-\mathrm{x}$

Im Originalbeitrag ist $\bullet$ Abb. 2 fehlerhaft.

Die Redaktion bittet um Beachtung der folgenden korrekten Abbildung.

\section{Korrespondenzadresse}

\section{Prof. I. Fietze}

Interdisziplinäres Schlafmedizinisches Zentrum, Charité - Universitätsmedizin Berlin Charitéplatz 1, 10117 Berlin, Deutschland ingo.fietze@charite.de
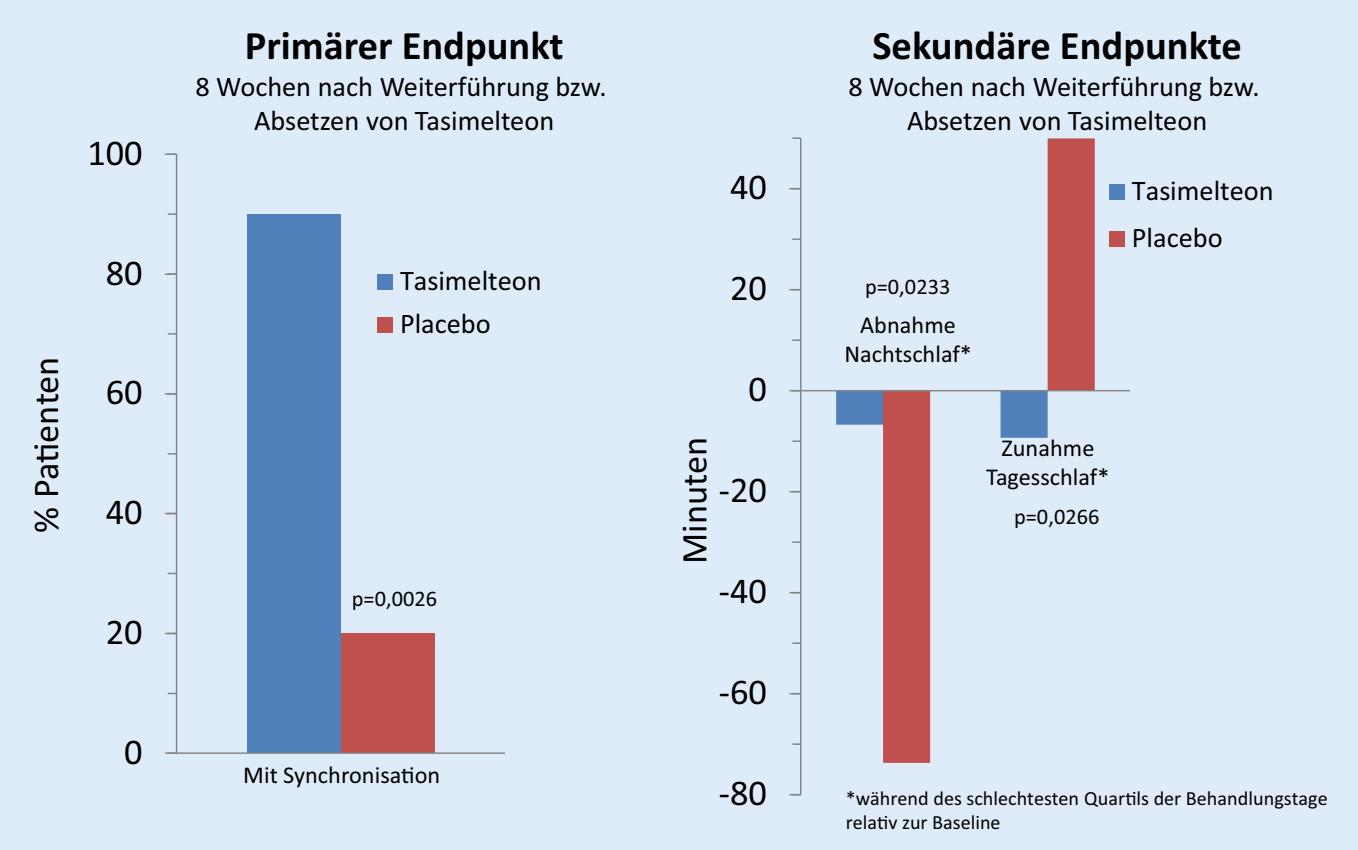

Abb. $2 \triangleleft$ RESET-Studie: Effekte des Absetzens von Tasimelteon bei Tasimelteon-synchronisierten vollblinden Patienten mit einem Nicht-24-Stundenzirkadianen Schlaf-WachSyndrom 